\title{
Biotransformation of Compactin to Pravastatin by Actinomadura sp. 2966
}

\author{
Yulin Penc ${ }^{\dagger}, J_{\text {Acob }}$ Yashphe $^{\dagger \dagger}$ and Arnold L. Demain \\ Fermentation Microbiology Laboratory, Biology Department, Massachusetts Institute of Technology, \\ Cambridge, MA 02139, U.S.A.
}

(Received for publication July 14, 1997)

\begin{abstract}
Actinomadura sp. strain 2966 can effectively convert compactin to pravastatin. The degree of conversion observed was $65 \%$ to $78 \%$ of compactin added and $65 \%$ to $88 \%$ of compactin taken up, depending on the concentration of compactin and duration of the experiment. Increasing the compactin concentration resulted in a higher final pravastatin concentration especially when compactin was added intermittently. Higher glucose concentrations had no effect on the bioconversion although uptake of compactin was inhibited. The conversion was linear over 16 hours. The system requires no induction and thus appears to be different from previously studied hydroxylases from actinomycetes.
\end{abstract}

High blood cholesterol, especially LDL-cholesterol, is causally related to coronary heart disease and the lowering of total and LDL-cholesterol levels reduces the incidence of coronary heart disease. 3-Hydroxy-3methylglutaryl (HMG)-CoA reductase is the rate-controlling enzyme in cholesterol biosynthesis. By inhibiting HMG-CoA reductase, plasma cholesterol levels in the body are reduced. Since the 1970s, several HMG-CoA inhibitors such as compactin, lovastatin and pravastatin have been discovered in fungal broths. They are very effective in lowering serum cholesterol in most animal species including humans ${ }^{1,2)}$. Pravastatin, an HMG-CoA reductase inhibitor clinically applied in the treatment of hypercholesterolemia ${ }^{3)}$, is produced by hydroxylation of compactin. Many fungi but extremely few actinomycetes are known to hydroxylate compactin to pravastati $n^{4,5)}$. In our previous paper ${ }^{5}$, we reported on a new microorganism, Actinomadura sp. strain 2966, which is able to effectively carry out this bioconversion. In this paper, we present our studies on this important activity.

\section{Materials and Methods}

\section{Chemicals}

Compactin was obtained from Fluka, Switzerland, and pravastatin from Squibb, U.S.A.

Organisms, Growth and Bioconversion Conditions Actinomadura sp. strain 2966 was isolated in South
Korea as a rare actinomycete by $\mathrm{S} . \mathrm{H}$. $\mathrm{BoK}^{5)}$. NZ medium was used to prepare slants; it contained (per liter): glucose $10 \mathrm{~g}$, soluble starch $20 \mathrm{~g}$, yeast extract $5 \mathrm{~g}, \mathrm{~N}-\mathrm{Z}$-amine $5 \mathrm{~g}$, agar $18 \mathrm{~g}$ (pH 7.3). YM medium, used as the liquid seed medium and growth and bioconversion medium, contained the following ingredients (per liter): glucose $10 \mathrm{~g}$, yeast extract $3 \mathrm{~g}$, malt extract $3 \mathrm{~g}$, peptone $5 \mathrm{~g}$ (pH 6.5). Compactin $(100 \mathrm{mg}$ ) was dissolved in $1.5 \mathrm{ml}$ dimethylformamide and $8.5 \mathrm{ml} 0.1 \mathrm{~N} \mathrm{NaOH}$.

The organism was inoculated from a slant grown for 7 days at $30^{\circ} \mathrm{C}$ into a $250-\mathrm{ml}$ Erlenmeyer flask containing $20 \mathrm{ml}$ of $\mathrm{YM}$ medium. After growth at $30^{\circ} \mathrm{C}$ with shaking (220 rpm) for $3 \sim 5$ days, $1 \mathrm{ml}$ of the seed culture was inoculated into 250-ml Erlenmeyer flasks containing $20 \mathrm{ml}$ of YM medium. After two days of growth under the same conditions as used for the seed culture, compactin was added and incubation was continued for one to seven more days. The degree of bioconversion is given on two bases: (i) percentage of compactin added to the culture; and (ii) percentage of compactin which has disappeared from the culture (i.e., used).

\section{Growth Determination}

$2.5 \mathrm{~N} \mathrm{HCl}(1 \mathrm{ml})$ was added to $1 \mathrm{ml}$ of whole culture broth followed by $3 \mathrm{ml}$ of water. The suspension was sonicated for 30 second at output 5 (Model W185, Heat System-Ultrasonics Inc. Plainview, N.Y. U.S.A.). The turbidity was measured on a Klett Summerson Colorimeter (Klett Manufacturing Co., New York, NY).

$\dagger$ Present address: Institute of Biology, Hebei Academy of Sciences, Shijiazhuang, P. R. China.

${ }^{\dagger}$ Present address: Bacteriology Department, Hebrew University/Hadassah Medical School, Ein Karan, Jerusalem, Israel. 
Table 1. Effect of time on bioconversion by strain $2966^{a}$.

\begin{tabular}{ccccc}
\hline $\begin{array}{c}\text { Days } \\
\text { after } \\
\begin{array}{c}\text { compactin } \\
\text { addition }\end{array}\end{array}$ & $\begin{array}{c}\text { Compactin } \\
(\mu \mathrm{g} / \mathrm{ml})\end{array}$ & $\begin{array}{c}\text { Pravastatin } \\
(\mu \mathrm{g} / \mathrm{ml})\end{array}$ & $\begin{array}{c}\text { Bioconversion } \\
\text { of } \\
\text { compactin } \\
\text { added }(\%)\end{array}$ & $\begin{array}{c}\text { of } \\
\text { compactin } \\
\text { used }(\%)\end{array}$ \\
\hline 1 & 32 & 252 & 50.4 & 53.9 \\
2 & 0 & 262 & 52.4 & 52.4 \\
3 & 0 & 290 & 58.0 & 58.0 \\
4 & 0 & 318 & 63.6 & 63.6 \\
5 & 0 & 326 & 65.2 & 65.2 \\
\hline
\end{tabular}

a Compactin was added at $500 \mu \mathrm{g} / \mathrm{ml}$ after 2 days of growth.

\section{Determination of Compactin and Pravastatin}

Compactin and pravastatin were determined by highperformance liquid chromatography (HPLC). Whole broth samples were centrifuged at $1500 \times g$ to eliminate cells, the supernatant fluids were filtered through $0.45 \mu \mathrm{m}$ filters and $10 \mu \mathrm{l}$ samples were injected into the column ( $3 \mu \mathrm{m}$ Superspher $100 \mathrm{RP}-18$ column, length $69 \mathrm{~mm}$, int. diam. $4 \mathrm{~mm}$, cat. no 50980 LiChroCART 75-4, EM Science, Gibbstown, NJ) of a Waters LC Module 1 HPLC apparatus. Solvents were as follows: mobile phase A: $2.5 \mathrm{~g} \mathrm{NaH}_{2} \mathrm{PO}_{4}$ dissolved in $800 \mathrm{ml}$ Milli-Q water; $200 \mathrm{ml}$ acetonitrile and $110 \mathrm{ml}$ methanol added; $\mathrm{pH}$ adjusted to 2.5 with $85 \% \mathrm{H}_{3} \mathrm{PO}_{4}$. Mobile phase $\mathrm{B}$ : mixture of $200 \mathrm{ml}$ water, $800 \mathrm{ml}$ acetonitrile, $110 \mathrm{ml}$ methanol and $1 \mathrm{ml} 85 \%$ $\mathrm{H}_{3} \mathrm{PO}_{4}$. Flow rate was $1 \mathrm{ml} /$ minute with the following gradient: $10 \% \mathrm{~B}$ ( $0 \sim 5$ minutes), 10 to $80 \% \mathrm{~B}(5 \sim 35$ minutes) and 80 to $10 \%$ B (35 55 minutes). Compactin and pravastatin were detected at $237 \mathrm{~nm}$, the UV absorption maximum. Retention times were 8.73 minutes for pravastatin and 25.03 minutes for compactin.

\section{Results}

Bioconversion During 5 Days of Incubation

Table 1 shows that most of the $500 \mu \mathrm{g} / \mathrm{ml}$ compactin which had been added after 2 days of growth had disappeared during the first day apparently being taken up into the cells. At this time, the conversion of compactin to pravastatin was about $50 \%$ of the compactin added. By the end of the second day, no compactin remained in the culture fluid. Apparently, there was still compactin in the cells since the pravastatin concentration steadily increased up to 5 days. The conversion by the fifth day reached $65 \%$.

\section{Effect of Glucose on Bioconversion}

To determine whether the concentration of carbon
Table 2. Bioconversion by strain 2966 of a higher compactin $(700 \mu \mathrm{g} / \mathrm{ml})$ addition ${ }^{\mathrm{a}}$.

\begin{tabular}{ccccc}
\hline $\begin{array}{c}\text { Days } \\
\text { after } \\
\begin{array}{c}\text { compactin } \\
\text { addition }\end{array}\end{array}$ & $\begin{array}{c}\text { Compactin Pravastatin } \\
(\mu \mathrm{g} / \mathrm{ml})\end{array}$ & $\begin{array}{c}\text { Bioconversion } \\
\text { of }\end{array}$ & $\begin{array}{c}\text { of } \\
\text { compactin } \\
\text { added }(\%)\end{array}$ & $\begin{array}{c}\text { compactin } \\
\text { used }(\%)\end{array}$ \\
\hline 0 & 678 & 0 & 0 & 0 \\
1 & 209 & 271 & 40.0 & 57.8 \\
2 & 149 & 311 & 45.9 & 58.8 \\
3 & 139 & 332 & 49.0 & 61.6 \\
4 & 137 & 349 & 51.5 & 64.5 \\
5 & 142 & 368 & 54.3 & 68.7 \\
6 & 152 & 405 & 60.0 & 77.0 \\
7 & 172 & 446 & 65.8 & 88.1 \\
\hline Compactin was added at $700 \mu \mathrm{g} / \mathrm{ml}$ after 2 days of growth.
\end{tabular}

source used for growth has any influence on the biotransformation, additional $(50 \mathrm{mg} / \mathrm{ml})$ glucose was added to the culture at the time when compactin $(500 \mu \mathrm{g} / \mathrm{ml})$ was added (after 2 days of growth) and the incubation was continued for 2 more days. No effect of the additional glucose was observed (data not shown).

In another experiment, increased concentrations of glucose were added to the YM medium at the time of inoculation. Levels of $25,50,75$ and $100 \mathrm{mg} / \mathrm{ml}$ of glucose were compared to the control level of $10 \mathrm{mg} / \mathrm{ml}$. We found that increased glucose concentration in the growth medium inhibited the rate of disappearance (uptake) of compactin from the medium but not its degree of bioconversion to pravastatin (data not shown).

\section{Bioconversion of a Higher Compactin Concentration}

We next determined whether the substrate concentration has an effect on the degree of conversion. A concentration of $700 \mu \mathrm{g} / \mathrm{ml}$ of compactin was added to the 2-day culture. The results are shown in Table 2. By comparing these data with those of Table 1 , it can be seen that the higher substrate concentration resulted in a slightly higher production of pravastatin (368 vs. $326 \mu \mathrm{g} / \mathrm{ml}$ at 5 days) and the conversion of added compactin was lowered ( $54 \%$ vs. $65 \%$ at 5 days), but the conversion of compactin used was about the same $(69 \%$ vs. $65 \%$ at 5 days). It thus appears that compactin at higher concentrations can be effectively bioconverted. By 7 days, almost $90 \%$ of used compactin had been converted to pravastatin.

\section{Intermittent Addition of Compactin}

In this experiment, $500 \mu \mathrm{g} / \mathrm{ml}$ compactin was added as 
Table 3. Bioconversion by strain 2966 with intermittent additions of compactin ${ }^{2}$.

\begin{tabular}{|c|c|c|c|c|c|}
\hline \multirow{2}{*}{$\begin{array}{c}\text { Days after first } \\
\text { compactin addition }\end{array}$} & \multirow{2}{*}{$\begin{array}{c}\text { Total compactin } \\
\text { added }(\mu \mathrm{g} / \mathrm{ml})\end{array}$} & \multirow{2}{*}{$\begin{array}{l}\text { Compactin } \\
(\mu \mathrm{g} / \mathrm{ml})\end{array}$} & \multirow{2}{*}{$\begin{array}{l}\text { Pravastatin } \\
(\mu \mathrm{g} / \mathrm{ml})\end{array}$} & \multicolumn{2}{|c|}{ Bioconversion $(\%)$} \\
\hline & & & & of compactin added & of compactin used \\
\hline 0 & 500 & 481 & 0 & 0 & 0 \\
\hline 1 & 500 & 0 & 271 & 57.3 & 57.3 \\
\hline $1^{b}$ & 800 & 304 & 258 & - & - \\
\hline 2 & 800 & 37 & 398 & 50.7 & 53.2 \\
\hline $2^{\mathrm{c}}$ & 1100 & 299 & 380 & - & - \\
\hline 3 & 1100 & 146 & 479 & 46.0 & 50.2 \\
\hline 4 & 1100 & 86 & 536 & 51.2 & 52.9 \\
\hline 5 & 1100 & 70 & 585 & 55.9 & 56.8 \\
\hline 6 & 1100 & 65 & 684 & 65.3 & 66.1 \\
\hline 7 & 1100 & 78 & 821 & 78.4 & 80.3 \\
\hline
\end{tabular}

a Compactin was added at $500 \mu \mathrm{g} / \mathrm{ml}$ after 2 days of growth, at $300 \mu \mathrm{g} / \mathrm{ml}$ one day later and at $300 \mu \mathrm{g} / \mathrm{ml}$ one day later

b Immediately after second compactin addition.

- Immediately after third compactin addition.

Fig. 1. Bioconversion dynamics of Actinomadura sp. strain 2966 during 36 hours.

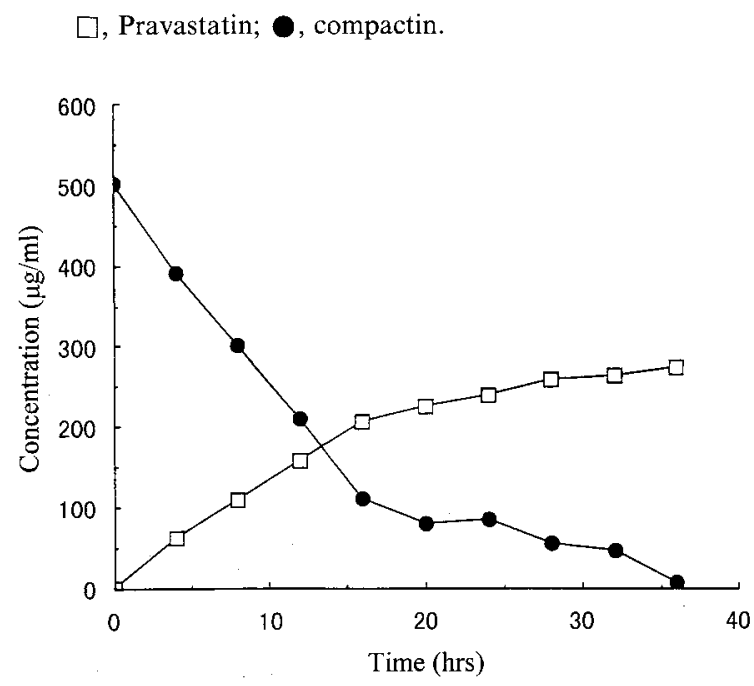

usual to the culture medium at 2 days, but an additional $300 \mu \mathrm{g} / \mathrm{ml}$ compactin was added on the third day and then again on the fourth day. The results are shown in Table 3. At 7 days after compactin addition, the highest pravastatin concentration observed in our studies $(821 \mu \mathrm{g} / \mathrm{ml})$ was reached and the degree of biotransformation ( $78 \%$ of added compactin) was also the highest. However, the $\%$ bioconversion achieved at 5 days was not increased over those listed in Table 1 or Table 2. Thus, adding compactin in shots does not affect the rate of bioconversion of compactin to pravastatin, but does lead to a higher final pravastatin concentration and a higher $\%$ bioconversion of added compactin.

Dynamics of Bioconversion by Strain 2966

Pravastatin production was examined at short in-
Table 4. The effect of culture age on bioconversion ${ }^{\mathrm{a}}$

\begin{tabular}{lcccc}
\hline $\begin{array}{c}\text { Culture } \\
\text { age } \\
\text { (days) }\end{array}$ & $\begin{array}{c}\text { Compactin } \\
(\mu \mathrm{g} / \mathrm{ml})\end{array}$ & $\begin{array}{c}\text { Pravastatin } \\
(\mu \mathrm{g} / \mathrm{ml})\end{array}$ & $\begin{array}{c}\text { Bioconversion (\%) } \\
\text { of } \\
\text { compactin } \\
\text { added }\end{array}$ & $\begin{array}{c}\text { of } \\
\text { compactin } \\
\text { used }\end{array}$ \\
\hline 2 (control) & 32 & 252 & 50.4 & 53.9 \\
4 & 3.6 & 267 & 53.4 & 53.8 \\
7 & 294 & 95 & 19.0 & 46.0 \\
\hline a & $500 \mu \mathrm{g} / \mathrm{ml}$ compactin added in this experiment at the time \\
& & & \\
shown in column 1 with incubation continued for 1 more \\
day.
\end{tabular}

tervals ( $3 \sim 6$ hours) in a 36 hour bioconversion of $500 \mu \mathrm{g} / \mathrm{ml}$ compactin (Figure 1). It can be seen that pravastatin production and compactin consumption were linear for the first 16 hours. After that, both rates slowed down.

The Effect of the Age of the

Culture on Bioconversion

To determine the effect of culture age on bioconversion by strain 2966, 2-day, 4-day and 7-day cultures were exposed to a compactin concentration of $500 \mu \mathrm{g} / \mathrm{ml}$ for 24 hours. The results are shown in Table 4 . It can be seen that cells grown for 4 days were slightly better in compactin uptake than a 2-day culture but equivalent in bioconversion. Cells grown for 7 days were much poorer in compactin uptake but only slightly poorer in bioconversion of used compactin.

\section{Discussion}

Actinomadura sp. strain 2966 has a strong ability to convert compactin to pravastatin. The $\%$ conversion 
reached a level greater than $50 \%$ in one day. In our experiments, up to $78 \%$ of the compactin added and up to $88 \%$ of the compactin used had been converted to pravastatin. Increasing the glucose concentration in the culture interfered with compactin uptake but did not affect the $\%$ bioconversion of compactin taken up, suggesting that the compactin was not used by cells as a carbon source and that the bioconversion of compactin taken up was not repressed by glucose. Increased charges of compactin added at the normal time of compactin addition or intermittently were converted very well, yielding higher pravastatin concentrations. Biotransformation started immediately after compactin was added into the culture, indicating that either induction of the hydroxylase is very rapid or may not be required. Hydroxylation of compactin to pravastatin in Streptomyces carbophilus is carried out by a cytochrome P450 system which must be induced with compactin ${ }^{6}$. To our knowledge, the extent of bioconversion effected by $S$. carbophilus has not been published. Cytochrome P450 systems found in actinomycetes active on other substrates also require induction ${ }^{7)}$. Thus the compactin hydroxylase of Actinomadura sp. strain 2966 appears to be different from the system in $S$. carbophilus and from those systems hydroxylating other substrates.

\section{References}

1) Fujioka, T.; F. Nara, Y. Tsujita, J. Fukushige, M. FuKami \& M. KuRoDa: The mechanism of lack of hypocholesterolemic effects of pravastatin sodium, a 3-hydroxy-3-methylglutaryl coenzyme A reductase inhibitor, in rats. Biochim. Biophys. Acta 1254: 7 12, 1995

2) Shepherd, J.; S. M. Cobbe, I. Ford, C. G. Isles, A. R. Lorimer, P. W. Macfarlane, J. H. MCKillop \& C. J. PACKARD: Prevention of coronary heart disease with pravastatin in men wih hypercholesterolemia. New Engl. J. Med. 333: $1301 \sim 1307,1995$

3) Nara, F.; I. Watanabe \& N. Serizawa: Development of a tranformation system for the filamentous, ML-236B (compactin)-producing fungus Penicillium citrinum. Curr. Genet. 23: 28 32, 1993

4) Endo, A.: The discovery and development of HMG-CoA reductase inhibitors. J. Lipid Res. 33: $1569 \sim 1582,1992$

5) Yashphe, J.; J. Davis, Y. Peng, S. H. BoK \& A. L. DEMAIN: New microorganisms which convert compactin to pravastatin. Actinomycetologia 11: 20 25, 1997

6) Matsuoka, T.; S. Miyakoshi, K. Tanzawa, K. Nakahara, M. Hosubuchi \& N. Serizawa: Purification and characterization of cytochrome P-450 $0_{\text {sca }}$ from Streptomyces carbophilus. Eur. J. Biochem. 184: 707 713, 1989

7) Sariaslani, F. S. \& C. A. Omer: Actinomycete cytochromes P-450 involved in oxidative metabolism: biochemistry and molecular biology. Crit. Rev. Plant Sci. 11: $1 \sim 16,1992$ 